\author{
Louis Hay \\ Institut des Textes \\ et Manuscrits Modernes
}

\title{
Obrona i iluminacja strony ${ }^{1}$
}

\section{Abstract \\ An Apology and Illumination of the Page}

The first part of the study is based on historical genetics. It examines the issues of the page over a long period of time and places it within the evolution of a written culture. In light of this past, the second part offers an integrated view of functions whose sequence creates the possibility of a genesis: a manipulable material object - a medium at the interface of thought and trace - a unit that measures the writing stages - a space where words and graphics interfere with the production of meaning. The conclusion points to another dimension of history: the future.

Słowa kluczowe: krytyka genetyczna, proces twórczy, historia kartki

Keywords: genetic criticism, creation process, history of the page

1 Polska wersja tytułu jest świadomą interpretacją francuskiej Défence et illustration de la page. We francuskim słowie ,illustration” wymiar poznawczy (wyjaśnianie za pomocą przykładów) jest równie silny jak estetyczny (grafika dodana do tekstu). W polskim słowie ,ilustracja” akcent przesuwa się nieznacznie na aspekt estetyczny. „Iluminacja” wydaje się w tym kontekście bardziej uniwersalna, jest zarazem rzucaniem światła (wyjaśnianiem), wydobywaniem z cienia (odkrywaniem), przydawaniem blasku (rehabilitacją), jest też materiałem graficznym współistniejącym obok tekstu i współtworzącym jego znaczenie (winietą, miniaturą, inicjałem). Każdy z tych elementów wydaje się prawdziwy w tej opowieści o stronie, jej dziejach i odkrywaniu jej znaczenia przez genetyków [przyp. tłum.]. Francuski tytuł artykułu jest parafrazą tytułu szesnastowiecznego traktatu $\mathrm{La}$ Défense et illustration de la langue française autorstwa Joachima du Bellaya [przyp. red.]. 
Dzisiejszy sposób postrzegania strony tekstowej świadczy przede wszystkim o rozdźwięku między dwiema dyscyplinami należącymi do tej samej dziedziny. Dla historyków kultury piśmienniczej pojawienie się strony stanowi wydarzenie o znaczeniu kluczowym, na równi z wynalezieniem pisma czy druku. Przykładowo zdaniem Anne Zali innowacja, którą była strona, „[...] przeobraziła głęboko praktyki intelektualne Zachodu, determinując ich kształt na kilka wieków” ", Jean Vezin mówi zaś o „prawdziwej rewolucji, którą - ze względu na wagę jej skutków - porównać należy do druku"3. Bez trudu można przytoczyć więcej takich cytatów, w tym punkcie środowisko naukowe jest jednomyślne. Przez długi czas opinia ta nie była jednak podzielana przez krytykę genetyczną. U początków tego nurtu stronę postrzegano albo jako przedmiot zbyt zwyczajny, by zasługiwał na uwagę badaczy: , ,...] powierzchnię neutralną, powierzchnię pomocniczą, co do której należy się zastanowić, czy może i czy powinna być opisywana w sposób znaczący", krótko mówiąc - [było to - dop. thum.] nic - w oczach Louisa Marina ${ }^{4}$, albo po prostu jako przedmiot, który wymykał się genetyce, o czym wspomina Pierre-Marc de Biasi ${ }^{5}$. Od tamtej pory tysiące stron przeszło przez ręce genetyków, służąc im w ich pracach. Badania skupiały się głównie na śladach, których nośnikiem jest strona: śladach pisanych oraz towarzyszących im elementach graficznych. Poza ów tradycyjny obszar zainteresowań wyszły najpierw nowatorskie badania zajmujące się analizą przestrzeni strony, potem zaś kodykologia rękopisów, zupełnie nowa dziedzina nauki, skupiająca się na informacjach, których może dostarczać papier. Stąd zaś już tylko krok do uznania tej wiernej towarzyszki genetyków nie tylko za element pomocniczy w badaniach, ale także za pełnoprawny przedmiot nauki ${ }^{6}$. Rola strony jako czynnika mającego aktywny wpływ na powstawanie dzieła ujawnia się w jej dziejach, ukazujących zarazem, jak konstytuowały się jej funkcje. Strona to kolejno materialne podłoże podlegające manipulacji - medium między myślą a jej fizycznym śladem jednostka wyznaczająca sukcesywne etapy pisania - przestrzeń, gdzie słowa i kształty oddziałują wzajemnie na siebie, tworząc znaczenie. W tym punkcie

2 L'Aventure des écritures, red. A. Zali, Paris 1998, s. 13.

3 J.Vezin,Lafabrication du manuscrit [w:] Histoire del'édition française, red. H.-J. Martin, R. Chartier, t. I, Paris 1982, s. 25. Należy również wspomnieć o wystawie zorganizowanej przez BnF w 1999 roku i o pracach powstałych przy tej okazji, poświęconych stronie (por. bibliografia na końcu artykułu).

4 Dessins et gravures dans le manuscrit de la Vie de Henry Brulard [w:] Écritures du romantisme I, Saint-Denis 1988, s. 109.

5 Pierre-Marc de Biasi: „,...] daleko nam jeszcze do tego, by móc stwierdzić, że mamy aparat pojęciowy pozwalający zainicjować dyskurs o organizacji plastycznej i przestrzennej rękopisu", zob. idem, Le manuscrit spectaculaire. Réflexions sur l'esthétique hugolienne de la mise en page autographe [w:] idem, De l'écrit au livre, Saint-Denis 1987, s. 201.

6 To podejście nie jest zresztą niczym wyjątkowym, wystarczy przypomnieć ważną monografię autorstwa Roberta Pickeringa z 1996 roku i wymienioną wyżej wystawę BnF. 
genetyka spotyka się z historią, która otwiera przed tą pierwszą głębię swoich możliwości. Ukazuje proces narodzin przedmiotu badań genetycznych, który stał się podstawowym narzędziem pisarza w naszych czasach. Historia tłumaczy teraźniejszość, pozwala jednak również lepiej zrozumieć przyszłość. Umieszcza bowiem rewolucję informatyczną jako jeden z etapów w długich dziejach słowa pisanego.

\section{Geneza}

\section{Wynalezienie kodeksu}

Prawdą jest, że z punktu widzenia krytyki genetycznej podejście historyczne ma swoją cenę. Wciąga nas ono w głąb wieków i zmusza do żmudnego, powolnego działania. Pierwsze świadectwo dotyczące wynalezienia kodeksu przenosi nas aż na początek naszej ery. Zawdzięczamy je Marcjalisowi, który zachwyca się tą nową formą słowa pisanego:

\section{Homerus in pugillaribus membraneis.}

Ilias et Priami regnis inimicus Ulixes

multiplici pariter condita pelle latent.

[Homer w kodeksach pergaminowych.

Ilion i Odys, wróg królestwa Priama,

W wielokroć złożonej skórze kryją się pospołu] $]^{7}$.

Wersy te są często cytowane, ponieważ pozwalają zarówno umiejscowić pewne zjawiska w czasie (Epigramy pochodzą z 85 roku), jak i opisać ich znaczenie. To, co budzi entuzjazm Marcjalisa, to fakt, iż kodeks pozwala nam ująć w ręce całe dzieło Homera. Kusząca jest również myśl, że jego własne utwory mogą towarzyszyć czytelnikowi choćby podczas dalekich podróży (Marcjalis, Epigramy, I, 2). Z reguły jednak świadkowie danego wydarzenia nie potrafi ocenić jego wagi. Tak też było i w tym wypadku - w wynalezieniu kodeksu starożytność nie dostrzegła wydarzenia o wymiarze rewolucyjnym dla sposobu pisania i myślenia, a jedynie technologiczne udogodnienie. Nowy materiał, pergamin, w połączeniu z procesem złamywania arkuszy w składki, pozwalał pisać po obu stronach uzyskanej w ten sposób kartki i zmniejszyć zużycie materiału. Dodatkowo niewielkie kodeksy pergaminowe, pugillaribus

\footnotetext{
7 Marcjalis, Epigramy, XIV, 184.
} 
membrane, okazały się dużo lżejsze niż tabliczki, a przez to wygodniejsze do sporządzania notatek. Zainteresowanie współczesnych nową technologią potwierdzają także inne świadectwa, jak choćby Kwintyliana ${ }^{8}$ czy św. Pawła ${ }^{9}$.

A jednak to nie w rzymskim uniwersum kodeks zaistnieje na dobre. Nie do końca rozumiemy przyczyny owej połowicznej porażki: historia strony jest wynikiem interakcji między czynnikami społecznymi, intelektualnymi i materialnymi, nie w pełni jeszcze rozpoznanymi. Prawdą jest jednak, że o losie kodeksu przesądziły nie nowe praktyki stricte piśmiennicze, a przemiana kulturowa, którą pociągnęła za sobą ekspansja młodej religii, którą było chrześcijaństwo. O przełomie tym mówi nam archeologia. Dysponuje ona niemymi wprawdzie, ale niepodważalnymi świadectwami: pierwszymi kodeksami, które zachowały się na Bliskim Wschodzie (por. il. 1). Pozwalają one uchwycić korelację między nową technologią a nową wiarą. Liturgia chrześcijańska znalazła w kodeksach medium uwalniające ją od ciężkich zwojów o długości 4-10 metrów, takich jak Tora. Ich miejsce zajęła pierwsza przenośna biblioteka, na którą składały się Ewangelie, zebrane i przewożone w jednej księdze. Dodatkowo forma kodeksu pozwalała na czytanie liturgii jako otwartej księgi. „Na stronie”, nowa funkcja niesie ze sobą praktykę swobodnego zestawiania kartek i możliwość obracania ich bez dotykania tekstu. To proste rozwiązanie, które znamy pod nazwą marginesu, odniesie w przyszłości niemały sukces.

Można zatem powiedzieć, że kodeks pokonał morze i przemierzył Zachód niesiony na skrzydłach nowej wiary. Ale statystyki, których dostarcza nam archeologia, pokazują, że trzeba będzie jeszcze kilku wieków, by stał się on podstawowym materiałem piśmienniczym. Dopiero w późnym średniowieczu jego zastosowanie do tekstów eklezjastycznych stanie się regułą. Także w tym wypadku możemy jedynie domyślać się przyczyn tak powolnej ewolucji. Siła przyzwyczajenia w pracy kopistów? Zanik praktyki pisania, która w ciemnych wiekach ograniczała się do klasztornych skryptoriów?

8 Ksztatcenie mówcy, X, 3-3-32.

92 List do Tymoteusza 4, 13. 


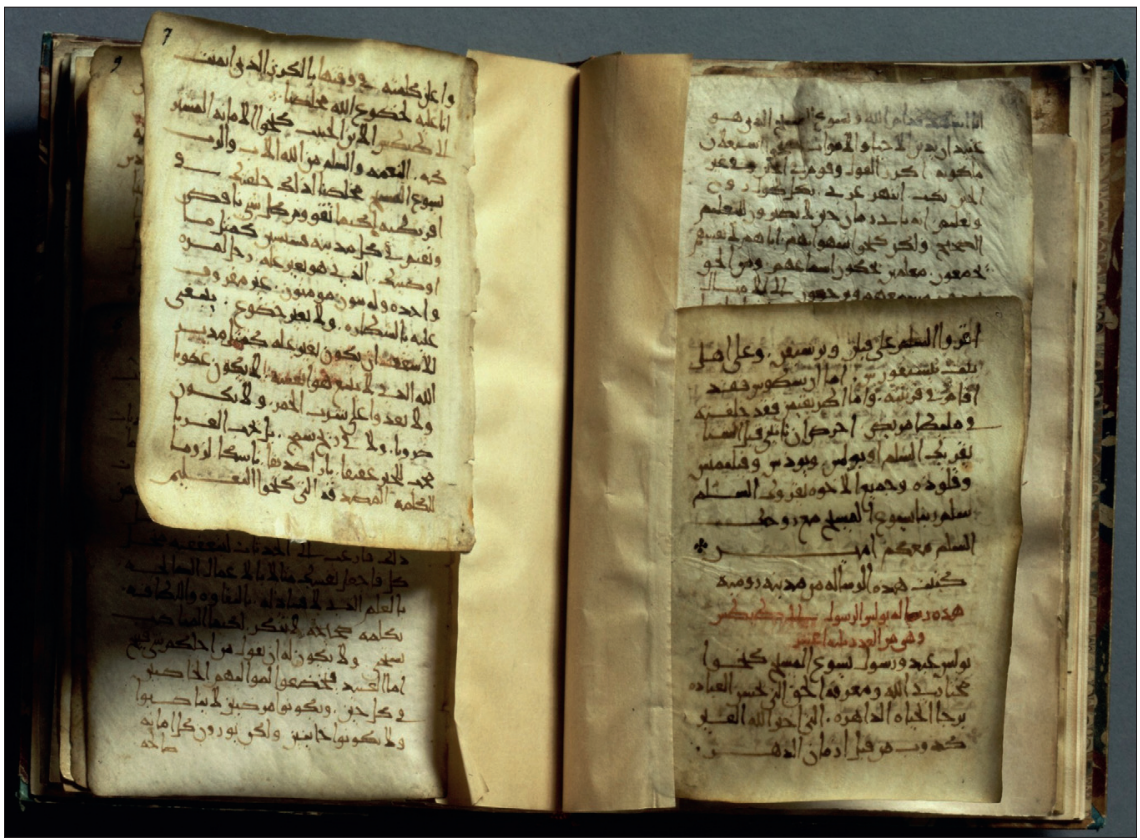

I1. 1. Kodeks heterogeniczny, z fragmentami Listów św. Pawła (Jerozolima, częściowo VI w.), pergamin

Źródło: BnF, Wydział Rękopisów, Arabski 6725, 6 v.-7 r.

\section{Powstanie strony}

Do końca średniowiecza strona współistnieje ze zwojem, który zawdzięcza swój prestiż wielowiekowej tradycji. Jeden z rękopisów z okresu późnego średniowiecza pokazuje św. Mateusza, który pracuje nad tekstem Ewangelii, zapisując go na stronie, podczas gdy towarzyszący mu anioł przekazuje boskie wskazówki, posługując się zwojem (por. il. 2). Wprowadzenie strony wiąże się również $\mathrm{z}$ dużą zmianą w zakresie przyzwyczajeń mentalnych. Wyznacza przejście od recytacji do lektury, od myślenia w kategoriach ciągłości do logiki sekwencyjnej. Proces pisania zostaje podzielony na etapy zgodne z rytmem zmieniających się kart. Dynamika intelektualna tej transformacji zawojuje proces pisania. Przerwana zostaje linia ciągła tekstu i uwidacznia się do tej pory niewidoczna figura języka: słowo. Strona zaś nada pisaniu ramy, w dwojakim sensie: jako prostokąt wyznaczający jego fizyczne granice i jako przestrzeń, w której po raz pierwszy słowa i niewerbalne elementy graficzne (ornamenty) składają się w jeden obraz $^{10}$. Tak rodzi się nowe postrzeganie przestrzeni i czasu pisania.

10 Upowszechnienie formatu prostokątnego jest istotnym etapem w przystosowaniu materiału piśmienniczego do fizjologii procesu pisania. 
Ale średniowieczna strona nie jest rozumiana jako część karty, nie jest też biała. Jest jedynie blokiem linii wyjustowanych $\mathrm{w}$ poziomie, ustawionych względem siebie w równych odstępach, jak to możemy zobaczyć na stronie z ilustracji 2 . Termin strona - pagina - który legitymizuje nową praktykę pisania, określa właśnie kolumnę tekstu, a nie materialną kartę będącą fizycznym podłożem dla tejże ${ }^{11}$.

Dopiero kolejna rewolucja w zakresie praktyk kulturowych pozwala wyjść poza takie rozumienie strony. Dochodzi do niej pod koniec ery monastycznej, z chwilą gdy pisanie opuszcza klasztorne skryptoria, by wkroczyć na uniwersytety. Teksty religijne nie są już wówczas przedmiotem publicznej lektury, są komentowane w zapiskach pojawiających się wokół tekstu głównego. Format kartki powiększa się, by móc pomieścić uwagi profesorów, a także notatki studenckie. Swoją drogą, teksty o charakterze świeckim pojawiają się oprócz tych wyłącznie religijnych, dzięki pierwszym transkrypcjom przekazywanych dotąd ustnie opowieści ${ }^{12}$. To, co dziś nazywamy „literaturą" i „stroną”, to dzieci tej samej epoki. Z czasem autografia zyskuje coraz większą popularność, pozwalając wydobyć ze strony jej największy atut, do tej pory traktowany marginalnie: umożliwia ona bowiem skryptorowi jednoczesne czytanie i pisanie.

Zapowiedź powstania instytucji brulionów w przededniu nowożytności jest zatem wynikiem wystąpienia kilku czynników. Ostateczny impuls do tego, by brulion zaistniał, daje rewolucja techniczna, która zmienia materialne warunki funkcjonowania autografii. Pojawienie się papieru we Włoszech i pierwsze znane bruliony pochodzące z XIV wieku uwalniają z kolei akt pisania od ograniczeń pergaminu, sprawiając, że jego udziałem staje się wolność intelektualna. Pióro przywraca do życia dawną technikę skreślania treści. Strona jest już kartką i jako taka umożliwia operacje manipulacji materialnej i permutacji tekstowej, które odegrały tak wielką rolę w powstawaniu tekstów nowożytnych. Pisarze bardzo szybko odkrywają zalety tych nowych możliwości. W rękopisach Petrarki widać już praktykę niepowstrzymanego niczym pisania, którą odnajdujemy na niektórych współczesnych stronach (por. il. 3). Tym samym zbliżamy się do najbardziej złożonej formy pisania: brulionu pokazującego narodziny utworu. Innowacje technologiczne nowożytności odcisnęły oczywiście swoje piętno na tym narzędziu, nie niszcząc jednak jego prostoty.

11 Łacińska poprzedniczka słowa „pagina” odnosi się m.in. do rzędów winorośli; w XI wieku słowo zmienia znaczenie i zaczyna określać linie pisania.

12 Jako przykład literatury świeckiej spisanej w języku francuskim można podać Pieśń o Rolandzie, w języku łacińskim - zbiór pieśni Carmina burana (Codex buranus). 


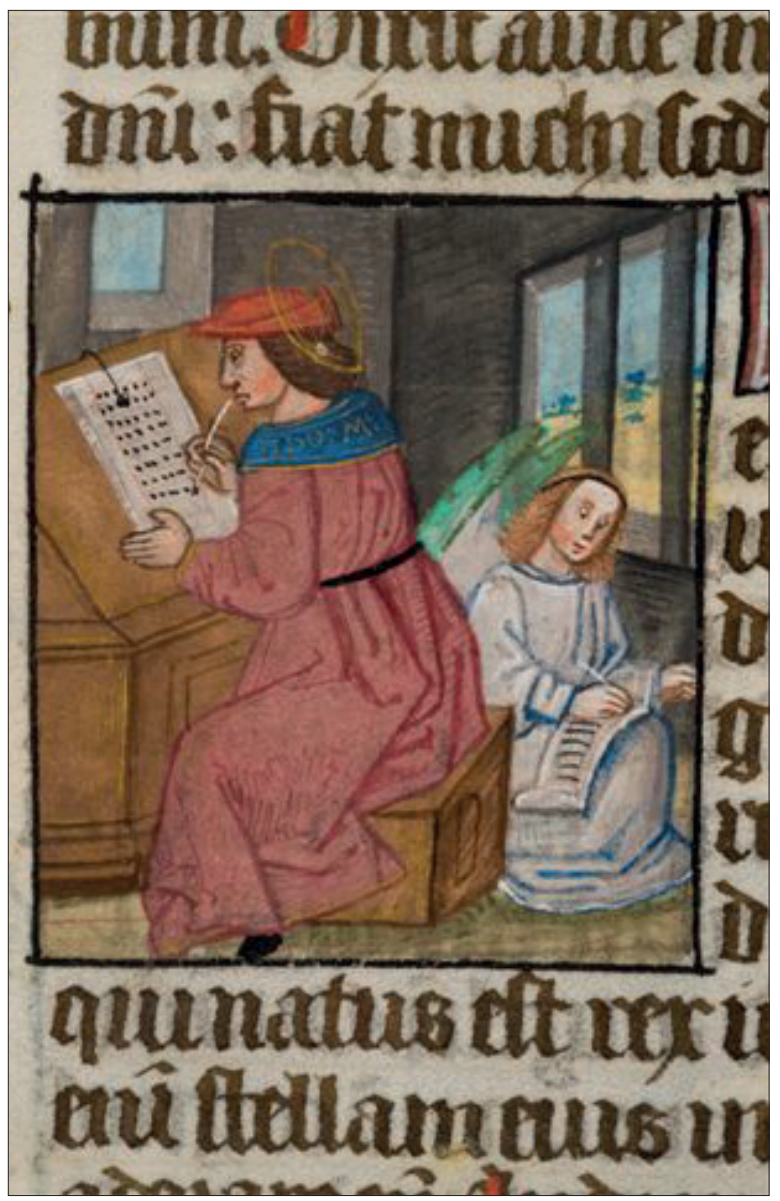

I1. 2. Ewangelista Mateusz, Livre d'Heures à l'usage de Rome, XV w.

Źródło: Médiathèque François-Mitterrand, Poitiers, M s. 51 5332, fotografia Olivier Neuillé. 
Il. 3. Francesco Petrarka, szkice do Sonetów do Laury (Vat. lat. 3196, f. 2 r.) (C) 2013, Biblioteca Apostolica Vaticana

Źródło: http://journals.openedition.org/genesis/docannexe/image/1216/img-3.png.

\section{Warsztat rękopisu}

Począwszy od włoskiego renesansu strona rękopiśmienna ewoluuje równolegle do strony drukowanej, która od niej się wywodzi i od której ta pierwsza zapożycza niektóre rozwiązania: paginę po obu stronach kartki, podział na rozdziały i paragrafy, zwyczaj pozostawiania lewego marginesu. To ostatnie zapożyczenie nie jest zresztą wcale funkcjonalne. W książce wymusza je konieczność łączenia kartek, ale podczas pisania ręka podążająca za tekstem przy lewym marginesie zakrywa ów tekst. Przede wszystkim jednak to w swojej materialności strona rozwija się najbardziej. Pisarze od dłuższego już czasu dysponowali niemałą paletą formatów: „Punkt wyjścia stanowiła, rzecz jasna, wielkość arkusza składanego jedno- lub dwukrotnie tak, aby było to przyjemne dla oczu, a pod prasę trafiała połówka lub ćwiartka zależnie od rosnącego rozmiaru papieru"13. Formaty folio (klasyczne ,jedno skrzydło" Laborde’a) przekraczały 30 x $20 \mathrm{~cm}$. Mamy z nimi do czynienia w rękopisach Petrarki, Angela Poliziana, Ludovica Ariosta i Torquata Tassa. We Francji odnajdujemy je jeszcze w XVIII wieku u Étienne'a de Condillaca i Jeana Antoine'a de Condorceta ${ }^{14}$. Od tego momentu zaczyna się ewolucja w kierunku wygodniejszych w użyciu formatów quarto, których rozmiar oscyluje około 25 x $19 \mathrm{~cm}$. Ten format upowszechni się zwłaszcza w XIX wieku ${ }^{15}$. Daleko nam jeszcze jednak do pełnej różnorodności formatów. Dopiero bowiem w 2. połowie XX wieku szereg „A" stanie się standardem międzynarodowym. W uprzemysłowionym XIX wieku strona rozpoczyna intensywny dialog z nowymi rozwiązaniami: zeszytem, który uwalnia pisarza od konieczności samodzielnego szycia składek, notatnikiem, dzięki któremu nie musi już zabierać kart do gry na przechadzki, jak czynił to Jean-Jacques Rousseau, notesem, który zastępuje dawne tabliczki. Ta różnorodność niepokoi niektórych ówczesnych badaczy i pisarzy, którzy zastanawiają się nad wpływem tylu nowości na sam proces pisa-

13 „The point of departure was apparently the size as used, folded once or twice, which was to pleasure the eye, and one double or quadruple of these was made on the mould as the dimension of these were increased". É.J. Labarre, Encyclopedia of Paper and PaperMaking, Amsterdam 1952.

14 Temat ten traktujemy bardzo pobieżnie; złożoność formatów i jednostek miary w okresie ancien régime'u nie może być tu brana pod uwagę.

15 Por. C. Bustarret, Usages des supports d'écriture au XVIII siècle: une esquisse codicologique, „Genesis” 2012, nr 34: „Brouillons des Lumières”, s. 54. 
nia, podobnie jak my zastanawiamy się dziś nad wpływem komputera ${ }^{16}$. Nic jednak nie potwierdza słuszności tezy o takiej korelacji. Dany rodzaj strony występuje w różnych epokach i u różnych pisarzy, o czym świadczyć mogą foliały, na których w XVIII wieku spisane zostały autografy Saint-Simona i Casanovy, ale również, nieco bardziej współcześnie teksty Émile’a Zoli, Paula Valéry'ego, Arthura Rimbauda, Claude’a Simona. Ten sam pisarz używa też różnych typów stron. U Valéry’ego pojedyncze arkusze zgięte na pół poprzedzały foliały, o których wspominaliśmy przed chwilą i które ze swej strony miały ustąpić miejsca szkolnym zeszytom, znamionującym przejście do pisania Zeszytów. Znajdujemy u niego również notatniki, a bruliony dzieł (Młoda Parka, Uroki, Mój Faust) pisane są najczęściej na pojedynczych wielkoformatowych arkuszach. Warto również wspomnieć o zupełnie przypadkowych materiałach: papierach pakowych, ryzie z nagłówkiem Ministerstwa Wojny, listach, kopertach ${ }^{17}$. O ile więc praktyki danego pisarza pozwalają badać relacje między tekstem a naturą jego nośnika, nie należy zapominać, że dla samego aktu pisania każde podłoże jest dobre. Wystarczy, by w odpowiednim momencie znalazło się pod ręką. Ta nadrzędna wolność pisarza w stosunku do używanego przez niego materiału przeczy tezie o determinującym wpływie tegoż na sam akt pisania. Dla badacza natura kartki nie dostarcza zatem informacji przyczynowo-skutkowych, podsuwa mu jedynie pewne wskazówki.

16 Por. D.F. McKenzie, Bibliography and Sociology of Texts, London 1986. Dla Wiktora Hugo, poezję można tworzyć wyłącznie na luźnych kartkach; używanie zeszytu świadczyło o mierności (Por. idem, William Shakespeare, t. I, § VIII; idem, Nędznicy, t. I, księga I, rozdział V). (We wspomnianym fragmencie eseju o Shakespearze pojawia się wyraziste przeciwstawienie talentów najwyższej i niższej rangi: ,[Shakespeare - dop. tłum.]. Pisał na luźnych stronach, jak niegdyś wszyscy poeci. Pewnie jedynymi, którzy pisali w zeszytach, byli Malherbe i Boileau". V. Hugo, William Shakespeare [w:] Euvres complètes de Victor Hugo. Philosophie II, Paris 1937, s. 13. W Nędznikach Hugo opisuje z kolei literacko-naukowe obyczaje „sprawiedliwego” biskupa Myriela: „Po wieczerzy rozmawiał z pół godziny z panną Baptystą i panią Magiorą; później wracał do pokoju swojego i zasiadał do pisania, to na ćwiartkach, to na marginesie jakiego voluminu. [...] Niekiedy, czytając jaką książkę, wpadał nagle w głęboką zadumę i ocknąwszy się, pisał kilka wierszy na kartach. Wiersze te często nie miały żadnego związku z treścią książki”. V. Hugo, Nędznicy, przeł. anonim, Warszawa 1900, s. 35 [przyp. red.]).

17 Związki między pisaniem a materiałem piśmienniczym badała głównie Nicole Celeyrette-Pietri wraz z grupą Valéry'ego z ITEM. 


\section{Genetyka}

Strona obiektem

Dzięki archeologii kodeksu dowiadujemy się, że wolność w zakresie traktowania strony w rozumieniu materiału piśmienniczego była faktem od początku chrześcijaństwa. Rękopis z ilustracji 1 pokazuje, że praktyki, po które później sięgał tak często choćby Marcel Proust, używane były już w tamtych czasach: luźna kartka włożona w środek zeszytu, połowa strony wycięta i przeniesiona w inne miejsce. W pierwszych wiekach naszej ery operacje te wykonywano nawet z większą starannością, ponieważ kopista dbał o to, by umieszczać kartki w zakładkach i je w ten sposób zabezpieczać ${ }^{18}$. Podobnie rzecz się miała w średniowieczu, kiedy używanie ksiąg złożonych z wielu niejednorodnych w sensie pochodzenia części było nierzadką praktyką. Strony lub wręcz całe składki przenoszone były z miejsca w miejsce, przestawiane, przebudowywane, a nawet ponownie wykorzystywane - pergamin był wszak drogi.

Działania te wydobywają na światło dzienne genezę ukonstytuowania się strony jako luźnej kartki, ale nie służą jeszcze jako narzędzie rzeczywistego procesu powstawania dzieła. $Z$ takim ich zastosowaniem mamy do czynienia dopiero w czasach nowożytnych. Jeden z pierwszych francuskich przykładów - i jeden z najbardziej znanych - to Myśli Blaise'a Pascala. Eksperyment, jakim są Myśli, wyznacza swoisty przewrót w historii krytyki genetycznej. Po raz pierwszy we Francji zastosowano zasady filologii do analizy cech materialnych rękopisu. Wiemy, że Pascal pisał na wielkoformatowych arkuszach, które następnie ciął i grupował według tematów, zwijając je w niewielkie rolki. W takiej postaci odnaleziono je w 1662 roku, a następnie przepisano i opublikowano w latach 1670-1678. Od tamtej pory strony te nie przestają fascynować wydawców. Każdy kolejny wiek przynosi kilkadziesiąt nowych i sprzecznych w swej strukturze wydań. Myśli weszły na stałe do prehistorii krytyki genetycznej (a właściwie, krótko mówiąc, do jej historii), kiedy w 1842 roku Victor Cousin na pięciu kolejnych posiedzeniach Akademii Francuskiej przedstawił poświęcony im raport. Jego analiza jest jedną z pierwszych pochwał rękopisu autorskiego: tylko ten ostatni pozwala uchwycić na żywo myśl autora i powiązać ją z problematyką zajmującą jemu współczesnych. Ostatnio Myśli stały się przedmiotem jednej z pierwszych wielkich analiz kodykologii genetycznej. Badając cechy materialne papieru, Pol Ernst zdołał odtworzyć i opublikować strony w takiej postaci, w jakiej zostały napisane, zanim jeszcze zostały pocięte ${ }^{19}$. Ilustracja 4 pokazuje kartkę, która jest stroną, ale nie

18 Warto przy okazji zwrócić uwagę na kolejną cechę szczególną: obecność paginacji recto verso, podczas gdy jej wprowadzenie przypisuje się zazwyczaj dużo późniejszej epoce.

19 P. Ernst, Les „Pensées” de Pascal. Géologie et stratigraphie, Oxford 1996. 
paginą w rozumieniu kolumny tekstu. Grupuje kilka spośród setek fragmentów znalezionych w dokumentach Pascala i zestawionych już po publikacji rękopisów. To odpryski myśli, czasem trzy słowa, czasem trzy zdania, rzucone nieoczekiwanie na kartkę, by wycięte następnie mogły utworzyć fragmenty przyszłej układanki. Wiemy, że takie podejście do strony nie jest czymś wyjątkowym: w ciągu wieków znajdujemy podobne przykłady. Wystarczy wspomnieć Gedanken und Einfälle Heinricha Heinego, okruchy myśli zapisywane przez kilka dziesięcioleci, dzieło, które odegrało kluczową rolę w badaniach genetycznych ${ }^{20}$. Podobnie w XX wieku zeszyty W Poszukiwaniu straconego czasu pozwalają zaobserwować sekwencje cięć i zestawień, poprzez które dzięki niesamowitej pamięci Proust mógł żonglować jednocześnie różnymi częściami powieści. Manipulacja pisarza materialnym nośnikiem stanowi tu istotną informację na temat powstawania dzieła ${ }^{21}$.

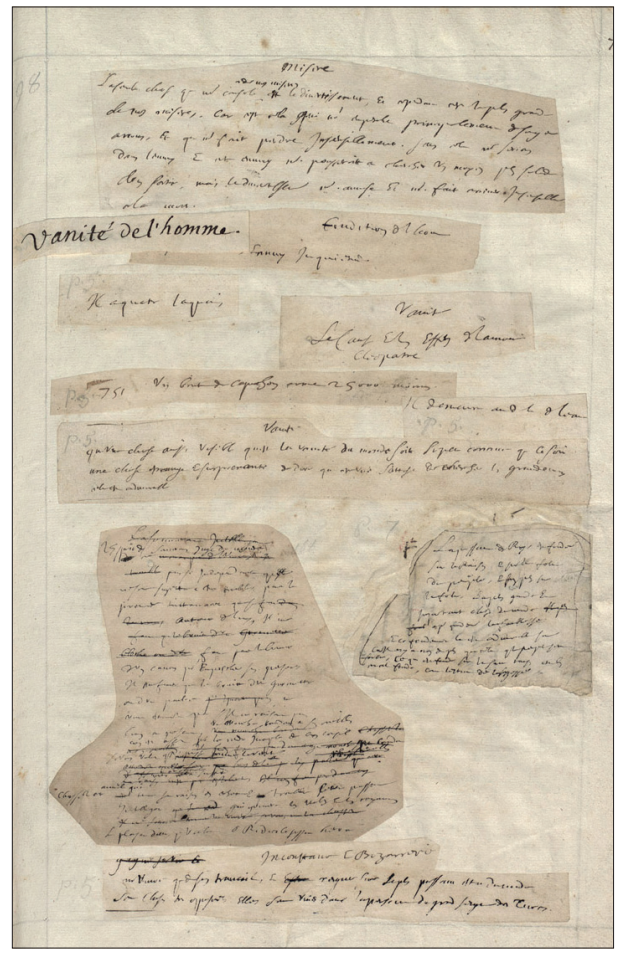

Il. 4. Blaise Pascal, Myśli

Źródło: BnF, Manuscrits français 9202, fo 79.

20 L. Hay, Le cas Heine [w:] idem, La Littérature des écrivains, Paris 2002, s. 315-329.

21 Por. B. Brun, Les cent cahiers de Marcel Proust. Comment a-t-il rédigé son roman?, www.item.ens.fr/index.php?id=13947, 2011; Proust aux brouillons, red. N.M. Dyer, K. Yosikawa, Turnhout 2010. 


\section{Materialność strony}

Z punktu widzenia badań genetycznych materialność strony posiada zatem dwa wymiary, zarazem współzależne i od siebie odrębne. Strona jest przedmiotem fizycznym, kartką papieru, noszącą ślady manipulacji, jakim była poddawana. To królestwo nożyczek i kleju, bez których nie powstałaby katedra, jaką jest $W$ poszukiwaniu straconego czasu. Ale jednocześnie strona jest nośnikiem pozwalającym zmaterializować się zamysłowi, medium między duchem a materią: to królestwo pióra. $\mathrm{Z}$ chwilą gdy pióro ustawia się na stronie, duch opuszcza swoją domenę, by zarządzać ręką - i oto stało się: słowo zaistniało. Przybrało materialną formę, wpisaną w trwanie, niezależną od ducha, od którego się oderwało. Pamiętamy frustrację Virginii Woolf, gdy nie starczyło jej strony:

I tak oto, w tym samym czasie, gdy warzę myśli i opisy do zapisania na tej kartce, mam bolesne poczucie, że kartki tu nie ma; że rozsypały się po podłodze. Zaiste trudno będzie je pozamiatać na powrót w całość ${ }^{22}$.

Za sprawą tych właściwości strona stała się sama tematem literackim, przywoływana bądź to jako przestrzeń wolności, otwierającej się przed piórem, bądź to jako granica między duchem a materią, granica przekraczana na mocy heroicznej decyzji. Ta dwoistość przebija w wersach Paula Valéry’ego:

W magicznym zwierciadle kartki dusza

widzi przed sobą przestrzeń cudów,

które zrodzą się ze znaków i linii.

Ta obecność nieobecnego podnieca i paraliżuje zarazem czyn nieodwracalny pióra.

[...] W końcu jednak dłoń podejmuje decyzję i niczym gracz

rzuca kartę na stół lub pionka

na szachownicę, tak ona zadaje nieskazitelności i integralności

możliwego cios - słowo, ślad - które przerwie $\operatorname{czar}^{23}$.

Ale strona nigdy nie jest tą samą stroną. Jest wielką białą kartą u Stendhala, prawie całkowicie pustą. Czysta powierzchnia, oczekująca na tekst, którego pióro nigdy nie powołało do istnienia. Jedynie drobne notatki wciśnięte na sam

22 „And thus, at the very time that I'm brewing thoughts \& descriptions meant for this page I have the heartbreaking sensation that the page isn't there; they're split upon the floor. Indeed, it's difficult to mop them up again". The Diary of Virginia Woolf, 18 kwietnia $1918 \mathrm{r}$.

23 P. Valéry, Przedmowa do inauguracji Muzeum Papieru w Ambert, „Bulletin d'études valéryennes" 1986, nr 42, s. 63. 
skraj strony: kilkadziesiąt linii nałożonych na siebie, każda z najwyżej trzema słowami. Zarysowują one ludzką sylwetkę (Niemca niewychwytującego francuskiej ironii), która nie pojawi się nigdy na stronach Lucjana Leuwena ${ }^{24}$ (por. il. 5). Na przeciwległym biegunie sytuuje się czarna strona André Bretona, wypełniona szczelnie tekstem Drugiego manifestu surrealizmu (por. il. 6, http://journals.openedition.org/genesis/docannexe/image/1216/img-6.jpg). Znamy też przykłady stron całkowicie pokrytych atramentem (takie jak u Jeana-Paula Goux czy Roberta Walsera), nieco tylko czytelniejszych od zupełnie nieczytelnej, wizualnie czarnej strony Podróży sentymentalnej Laurence'a Sterne'a. Nieważne jednak, że czy biała, czy czarna od liter, strona nie jest nigdy pusta. Christoph Meckel wspomina o karcie, na której widnieje tylko jedno słowo („Nacht”): zawiera ona poemat, który dopiero powstanie. Zawsze pełna, strona jest też zawsze unikatowa. Raz rozpocząwszy pisanie na jednej stronie, trudno przerzucić się na kolejną. Każdy zna końcówki stron, na których tekst zagęszcza się intensywnie, by zmieścić się w obrębie jednej przestrzeni. O tym obsesyjnym przywiązaniu pisma do integralności przestrzennej i wizualnej świadczą również różnorodne wybiegi stosowane przez pisarzy. Czasem są to bardzo proste rozwiązania - fragmenty kartek doklejone do strony, jak u André Bretona (por. il. 6), czasem wręcz ekstremalne - następujące po sobie dodatki u Jeana Paulhana, papiery rozwijane z różnych stron u Prousta. W trakcie długiej wspólnej historii dłoń i strona dopasowywały się do siebie coraz ściślej, by w końcu zespolić się w jedno spójne narzędzie pisarza. Przede wszystkim jednak strona posiada rozstrzygającą moc udostępniania do wglądu systemu znaków zamkniętych w obrębie jednej przestrzeni. Współistniejąc obok siebie, składają się one w kompleksową całość graficzną, której sens tworzy się w relacjach między poszczególnymi elementami ${ }^{25}$. Narzędzie pisania staje się jego podmiotem, wewnętrzna struktura strony współtworzy bowiem sens. Mówiąc o Stéphanie Mallarmém, Paul Valéry stwierdzi któregoś dnia: „Cały jego geniusz opiera się na uwadze skierowanej na stronę jako jedność materialną"26.

24 Por. J. Neefs, Stendhal sans fins [w:] idem, Le Manuscrit inachevé, Paris 1986, s. 27.

25 Wraz z wydaniem genetycznym strona, rozumiana jako rama i jako jedność znaczenia, posłuży do strukturyzacji modeli reprezentacji.

26 P. Valéry, list do dyrektora Margesa, OEuvres complètes, Gallimard, coll. „Bibliothèque de la Pléiade", Paris 1957, t. I, s. 626-627. 


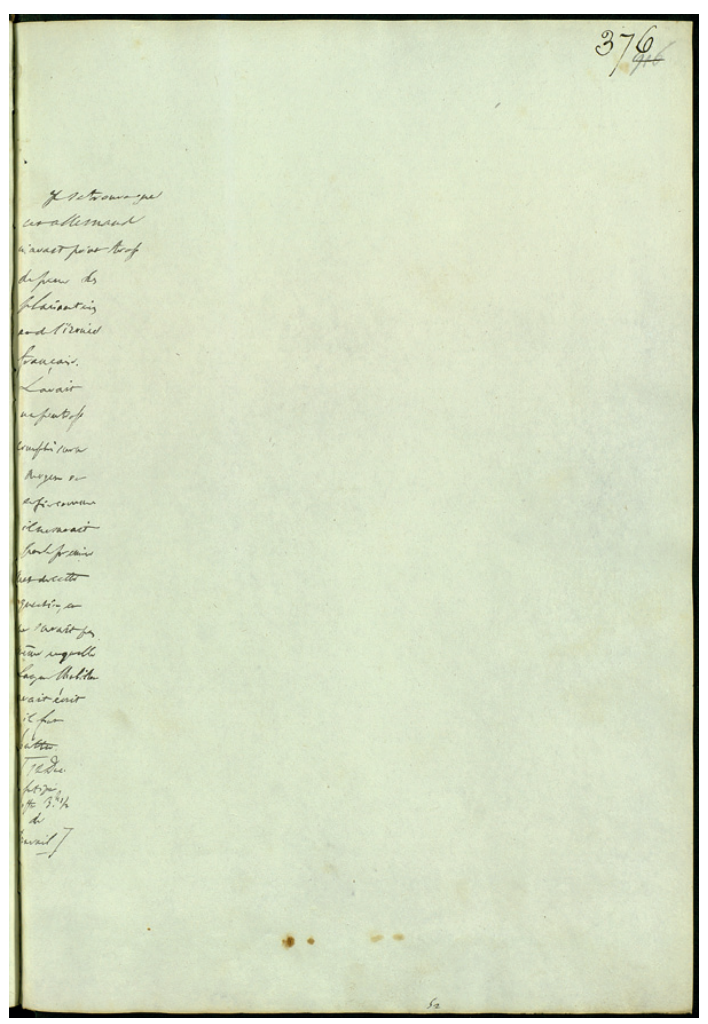

Il. 5. Stendhal, rękopis Lucjana Leuwena (ostatnia część)

Źródło: Bibliothèque municipale de Grenoble, R301(1) Res., f. 376.

\section{Przestrzenie}

Unikatowa relacja ta jest zarazem niezwykle różnorodna za sprawą bogactwa osobowości autorów i wskutek dwóch praktyk, które pisarstwo stosowało już wcześniej w niektórych epokach, a które naznaczyły brulion, gdy stał się on głównym narzędziem twórczości literackiej. Pierwsza to takie układanie treści na stronie, które pozwala wychwycić sekwencje czasowe i struktury przestrzenne powstawania dzieła. Druga związana jest z pojawieniem się niewerbalnych elementów graficznych, które przenoszą sens poza ten zawarty w samych słowach. Plastyczność obu tych wymiarów genezy dzieła przekłada się na wielość indywidualnych realizacji, otwierających przed teorią genetyki szerokie pole badawcze.

Przestrzeń strony należy do wszystkich, ale tylko autor organizuje ją na swój sposób. Krytyka badała dogłębnie różnorodne metody wykorzystania marginesu, rozwiązania, które spotkaliśmy w późnym średniowieczu pod postacią glosy i którego dzieje śledziliśmy aż do jego współczesnego wcielenia. 
Wiktor Hugo, powieściopisarz „bez brulionów” (Jean Gaudon), rezerwuje połowę strony na treść pomocniczą, tę, której jeszcze nie ma, ale która pewnego dnia pojawi się i zburzy porządek istniejącego tekstu; u Gustave'a Flauberta margines pełni różnorodne funkcje: czasem jest to informacja, która wzbogaca tekst główny, czasem antycypacja, która go przygotowuje, czasem szkic nadający mu kontury; u Francisa Ponge'a jest on przestrzenią zarezerwowaną dla tego, co minimalne, a zarazem najważniejsze: miejscem na kroplę na źdźble trawy, niuans niuansu danego słowa; u Valéry'ego na marginesie lądują słowa-filary (słońce, brzeg, wiatr) promieniujące na cały tekst. Z jeszcze większą swobodą pisarze traktują wolną przestrzeń poza marginesem. Jej organizacja jest istotnym składnikiem procesu powstawania dzieła i jednym z ulubionych zagadnień badawczych. Z braku możliwości przeglądu tak szerokiego spektrum zjawisk postanowiłem ograniczyć się do momentu rzeczywistego pisania, gdy obraz strony zaczyna się kształtować. W tym zakresie uderza istnienie dwóch skrajnie różnych postaci: fragmentacji i kompozycji, pomiędzy którymi rozpościera się wielobarwny kobierzec możliwych struktur. Przeanalizuję zatem wyłącznie przykłady tych dwóch przeciwnych logik, które ze swej strony mogą przybrać bardzo różnorodne formy. I tak u Jules'a Romains rozkładówka pokryta jest wieloma zakreśleniami (por. il. 7), z czego każde zawiera zaledwie kilka słów. Między poszczególnymi słowami nie ma związku semantycznego, łączy je układ graficzny, który albo oddziela od siebie zakreślenia, albo je wchłania, tworząc z nich jedną strukturę. Podobna forma graficzna zakreślenia słów rozrzucone na stronie - pojawia się u Waltera Benjamina (rękopis Pasaży), a zatem w tekście o zupełnie innym charakterze. U Jeana Anouilha (w Damie nocy) króciutkie fragmenty tekstu otoczone są prostokątnymi ramkami i umieszczone $\mathrm{w}$ nieładzie na stronie $\mathrm{w}$ nakładających się na siebie warstwach. Podobnie chaotyczny układ zakreślonych słów znajdujemy u Roberta Musila (por. il. 8). Z drugiej strony mamy powierzchnie zorganizowane logicznie w gigantyczne figury geometryczne. Tak wyglądają strony u Heinricha Bölla (por. il. 9, http://journals.openedition.org/genesis/docannexe/image/1216/img-9.jpg), u którego użycie kolorów przekształca owe figury w prawdziwe abstrakcyjne obrazy. Kolory odgrywają również istotną rolę na kartach Drogi przez Flandrię i sam Claude Simon tak tłumaczy ich funkcję:

Rozwiesiłem wszystko na ścianach w biurze i zacząłem się zastanawiać, czy nie należałoby dodać gdzieniegdzie nieco niebieskiego, gdzieniegdzie nieco zielonego, żeby uzyskać większą równowagę. Co ciekawe, ,sfabrykowałem” niektóre ustępy, ponieważ w tym akurat miejscu brakowało zielonego albo różowego. A nie było to w ogóle moim zamysłem na początku ${ }^{27}$.

Słowa te, często cytowane, uwidaczniają coś, co można by określić jako sprzężenie zwrotne: oddziaływanie istniejącego już rękopisu na twór-

27 Claude Simon w kontekście Drogi przez Flandrię, Seminarium w Cerisy, 1975. 
cę, sprawiające, iż rękopis ten staje się czynnikiem sprawczym procesu powstawania dzieła. Eksperyment Claude'a Simona pokazuje również, że nawet $\mathrm{w}$ najbardziej abstrakcyjnym modelu kompozycyjnym pisarz jest zaangażowany całą swoją osobą. Nic nie świadczy o tym dobitniej niż przykład Georges'a Pereca:

Piszę: mieszkam w mojej kartce papieru, obejmuję ją w posiadanie, przemierzam ją. Tworzę białe plamy, puste przestrzenie (przeskoki w sensie: nieciągłości, przejść, przenikania się elementów) ${ }^{28}$.

Zjawisko to ilustrują materiały robocze do Życia. Instrukcji obstugi. Stronę przedstawioną na ilustracji 10 elementy graficzne wypełniają tak gęsto, że zdają się wylewać poza jej krawędzie, podczas gdy w rzeczywistości nie powinna ona zawierać nic oprócz listy umieszczonej przy lewej krawędzi. Pamiętamy, że każdy z rozdziałów Życia ma używać 42 słów z listy. Odstępstwa - jak „fałsz”, „brak” - pomyślane są jako elementy zakłócające automatyzm systemu, a cyfry na górze wskazują na umiejscowienie strony w układzie matematycznym (po lewej) i tekstowym (po prawej). Niektóre rozdziały w tych materiałach to rzeczywiście puste lub prawie puste strony, na których widnieją jedynie listy. Inaczej jest w tym wypadku. Lista wysuwa się na pierwszy plan za sprawą kumulacji graficznych wyróżników: czerwonego markera, słów w czerwonej ramce - upodobanie Pereca do list nie budzi wątpliwości. Ale już tutaj elementy listy zaczynają przelewać się, obejmując w posiadanie otaczającą je wolną przestrzeń: „kamień półszlachetny” staje się, na prawo, kompletną biżuterią: „owalnym oczkiem z korundu (opalizującego) z trzema sygnaturami”, by przerodzić się, na lewo, w niewielki szkic zaczynający się od słów: „Na palcu nosi pierścionek [...]”. Przede wszystkim jednak, „pompa uruchamiająca wyobraźnię" generuje na brzegu listy kolumnę figur geometrycznych, ślad niczym nieskrępowanego biegu wyobraźni. I, w sposób spektakularny, ów moment zawieszenia aktu pisania uruchamia język. Czasami w detalu dekoracji czy ubrania, czasami we fragmencie narracji fraza odzyskuje swoje prawa - zatrzymana na chwilę przez rower, który pędzi od alfy do omegi. To fragmentaryczne pisanie zostanie z kolei zawieszone na rzecz sekwencji graficznej, odznaczającej się bardziej abstrakcyjnymi formami i dopracowanym cieniowaniem. Cała pusta przestrzeń strony ginie ostatecznie w owej powodzi znaków, w której słowa i formy przenikają się naprzemiennie.

28 G. Perec, Espèces d'espaces, Paris 2000, s. 23. 
Il. 6. André Breton, rękopis Drugiego manifestu surrealizmu (zbiory prywatne, Musée des lettres et manuscrits, Paryż)

Źródło: http://journals.openedition.org/genesis/docannexe/image/1216/img-6.jpg.

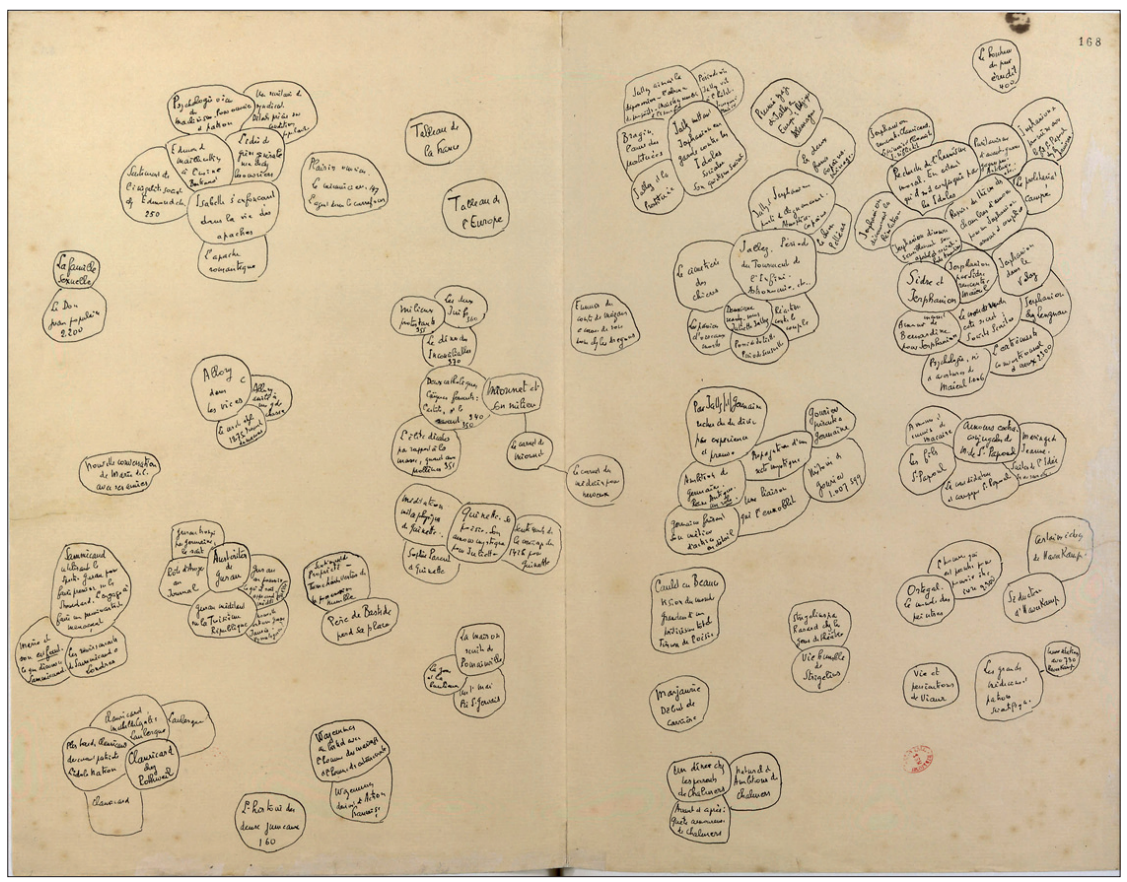

Il. 7. Jules Romains, rękopis Ludzi dobrej woli

Źródło: BnF, Fonds Jules Romains, t. I, f. 167 v. -168 r. 


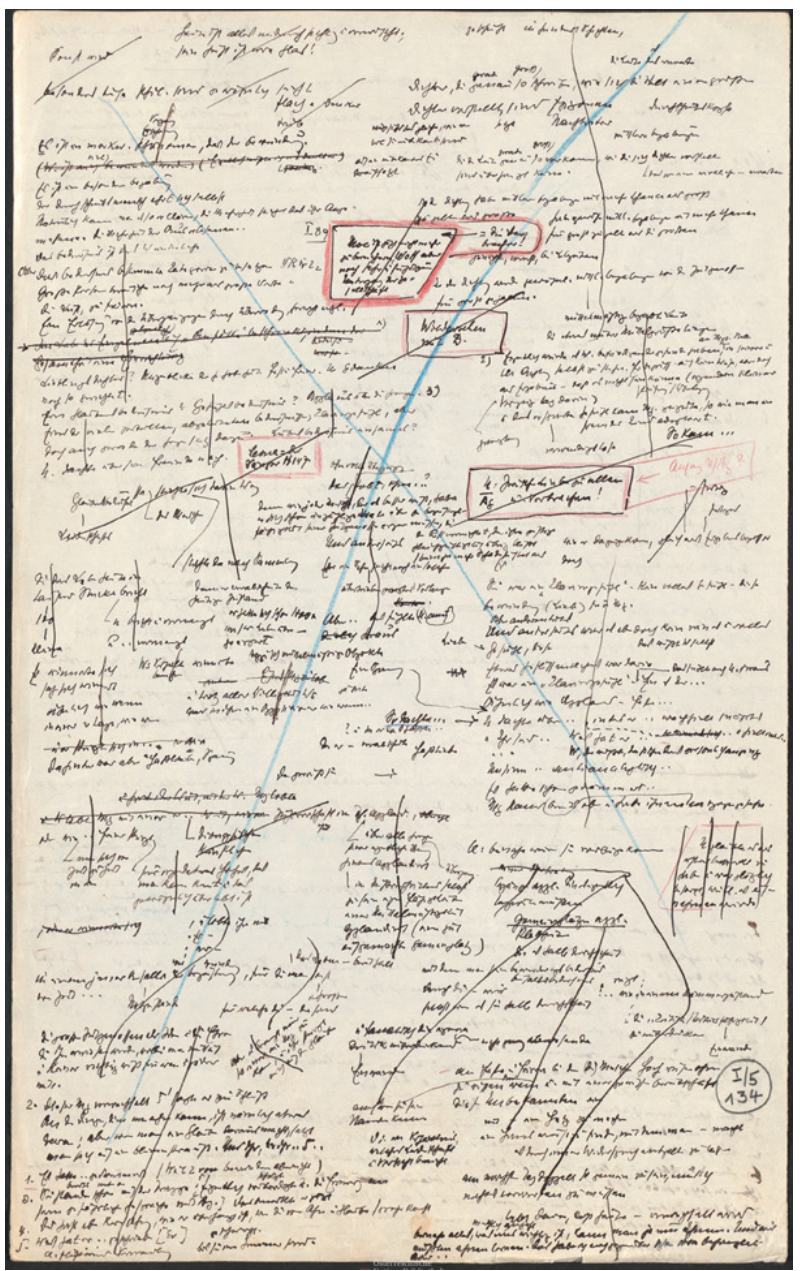

Il. 8. Robert Musil, Człowiek bez właściwości

Źródło: Österreichische Nationalbibliothek, Handschriften-Autographen-und-Nachlasssammlungen, HAN, Ser. nov. 15065, Mappe I/5, S. 134.

Il. 9. Heinrich Böll, plan poszczególnych części i zarys bohaterów do Portretu grupowego $z$ dama (Heinrich-Böll-Archiv, Kolonia)

Źródło: http://journals.openedition.org/genesis/docannexe/image/1216/img-9.jpg. 


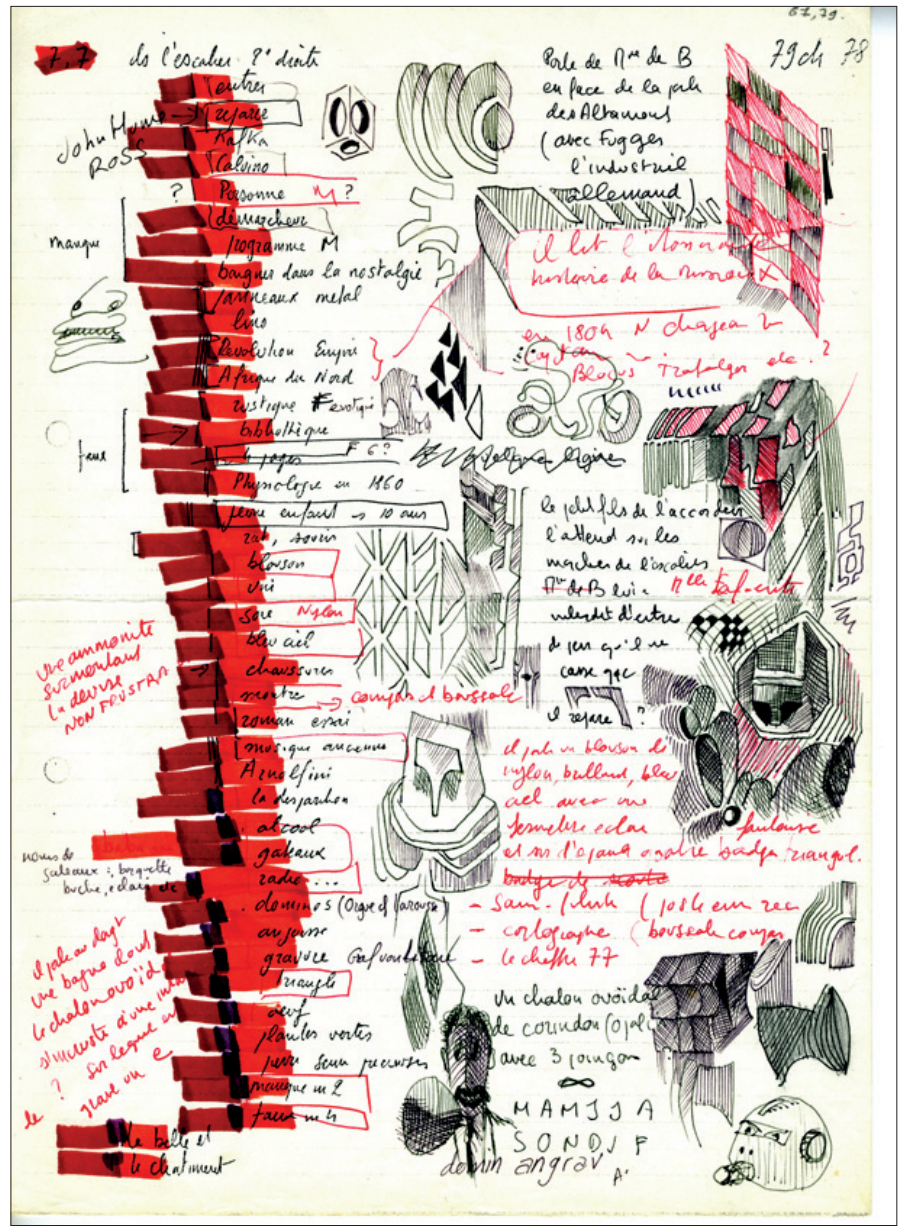

Il. 10. Georges Perec, Materiały robocze do Życia. Instrukcji obstugi, f. 78 (roz. 78) Źródło: zbiory prywatne, Bibliothèque de l'Arsenal, digitalizacja Jean-Luc Joly.

\section{Elementy graficzne}

Na pierwszy rzut oka doświadczenie Pereca wydaje się potwierdzać tradycyjne postrzeganie pisania jako strumienia atramentu wypływającego z pióra, by powołać do istnienia słowa i kształty. Ten obraz odpowiada pewnej rzeczywistości graficznej: werbalne czy nie, inskrypcje współdzielą tę samą przestrzeń, tę samą chwilę i bardzo często to samo pióro. Ale nie są pochodną tych samych operacji umysłowych. W tym względzie badania kognitywne przypominają nam o pewnych oczywistościach: reprezentacja rysunku nie tworzy się w sferze językowej, jego wykonanie nie przechodzi przez ośrodek odpowiedzialny za pisanie, a akt jego stawania się nie jest wynikiem praktyki. 
Słowa i kształty związane są z dwoma odrębnymi porządkami myślowymi. By zrozumieć prawdziwie proces powstawania dzieła, trzeba wiedzieć, w jaki sposób obie te sfery komunikują się ze sobą.

W genezie dzieł literackich, rysunki nie pokazują, one znaczą. Sylwetka kadłuba w Młodej Parce nie ukazuje statku, ale ustanawia prawo paralelnych linii; zegar nie podaje godziny, ale mówi o nieustannym oscylowaniu „między formą a treścią, dźwiękiem i znaczeniem, poematem a poezją" (Paul Valéry). Krytyka podejmuje się odszyfrowywania znaków; odkrywa w śladach pióra dwie warstwy, werbalną i niewerbalną. Nie analizuje wartości estetycznej kształtu i nie stara się ustalić jego referentu. Jej celem jest jedynie uchwycenie roli tego pierwszego w powstawaniu utworu. Weźmy przykład Stendhala i Émile'a Zoli. Jeden i drugi rysują plany wyobrażające miejsca akcji, odręcznie, z równą niezdarnością, która sprawia, że dodatkowe opisy słowne okazują się nieodzowne do zrozumienia idei autora. Istotne jest jednak to, że u obu elementy graficzne pełnią inną funkcję w procesie powstawania dzieła. Rysunek, w Życiu Henryka Brularda, przywołuje przeszłość, umożliwiając tym samym powrót do miejsc ze wspomnień: „mojego pokoju”, „mojej szafy”. Gdy narracja opuszcza czasy dzieciństwa, grafika już jej nie towarzyszy. U Zoli rysunek poprzedza narrację. Przygotowuje ją, buduje scenerię i umieszcza w niej akcję. U Stendhala grafiki nie mają werbalnego charakteru, u Zoli mieszają się ze słowami, uruchamiają język, inicjują narrację. Rolę grafiki jako impulsu skutkującego powstaniem treści odnajdujemy również u Prousta, Valéry'ego czy Grassa. U Claude'a Simona rysunek staje się wręcz jednym z bohaterów narracji. W Bitwie pod Farsala szkic poprzedza tekst, który staje się werbalnym odbiciem ilustracji (por. il. 11).

Akt rysowania inspiruje również pisarza do przedstawienia samego procesu pisania $\mathrm{w}$ formie swoistego autoportretu - obrazu dłoni trzymającej pióro nad stroną, białą niczym płótno malarza. W tym wypadku ilustracja stanowi wstęp do tekstu niczym drzwi otwierające się na inną przestrzeń. Zwierciadło tekstu odsyła pisarzowi jego odbicie w widoku jego dłoni tworzącej właśnie fikcyjne światy. Ta dualność ducha, który myśli, i ciała, które pisze, nie przestawała prześladować Valéry'ego, skąd zapewne liczne rysunki, w których uwiecznił swoje dłonie i twarz. Także Puszkin pokazuje na swój sposób dualizm ciała pisarza: na jednej ze stron Eugeniusza Oniegina przedstawia siebie ściskającego dłoń bohatera swojej powieści. Z kolei Günter Grass interpretuje dosłownie metaforę lustra: umieszcza się przed lustrem, by doprowadzić do konfrontacji ze swoim podwójnym odbiciem: człowieka i poety (por. il. 12). W tym, co jest bez wątpienia pierwszym brulionem wiersza zatytułowanego Jak widze siebie (Wie ich mich sehe), umieszcza słowa i rysunki: „Widzę się w lustrze/ swoje opadające powieki// rzuciłem wyzwanie/ władzy i pieniądzom// moje 
powieki opadają ale oddech niezmiennie unosi piórka i wszystko co fruwa na wietrze"29. Autoportret, rysunki, słowa warunkują się wzajemnie, dokładnie takie, jak wpisano je na stronę.

Il. 11. Claude Simon, rękopis Bitwy pod Farsala (zbiory prywatne)

Źródło: http://journals.openedition.org/genesis/docannexe/image/1216/img-11.jpg.

I1. 12. Günter Grass, rękopis Jak widzę siebie (C Günter Grass, Steidl Verlag, Göttingen) Źródło: http://journals.openedition.org/genesis/docannexe/image/1216/img-12.jpg.

29 Transkrypcja oddaje niedoskonale układ fragmentów; ostateczny tekst utworu Wie ich mich sehe znajduje się w Günter Grass, Der Butt, Darmstadt 1977, s. 116. Polski przekład opiera się na francuskim tłumaczeniu brulionu. Ostateczna wersja wiersza Jak widzę siebie, którą podajemy poniżej, jest dostępna w thumaczeniu Leona Kasajewa w zbiorze: idem, Wiersze wybrane, wybór, oprac. i posł. B. Fac, Gdańsk 1986, s. 166 [przyp. tłum.].

Jak widzę siebie

Odwrotnie w lustrzanym odbiciu i wyraźnie krzywo.

Już trzepoczą nadmiernie powieki górne.

To jedno oko tkwi zmęczone, podstępnie to drugie czujne.

To tyle wglądu i intymności,

po tym, jak głośno wielokrotnie

potęgę i jej posiadanie zagłuszyłem szczekaniem.

(Będziemy! Będzie! Tak musi być!)

Ujrzyjcie poorane policzki.

Jeszcze lub znów: lekko dmucham w pierze

i utrzymuję, co szybuje.

Chciałby widzieć podbródek, kiedy drżeć mu wolno wreszcie.

Czoło stawia czoła: całości brakuje idei.

Gdzie, kiedy ucho jest przesłonięte

lub oddane innym obrazom,

zagnieżdża się śmiech w okruchach?

Wszystko jest zacienione i otulone doświadczeniem.

Okulary odłożyłem na bok.

Tylko z przyzwyczajenia węszy nos.

Z warg,

które wciąż dmuchają pierze, odczytuję pragnienie.

Pod wymieniem biało-czarnej krowy:

widzę siebie pijącego

lub u twojej szyi, kucharko,

po tym, jak twoja pierś zwisała

kapiąc, nad gotującą się rybą;

uznasz mnie za pięknego.

[przyp. red.] 


\section{Znikanie i pojawianie się}

Tematyka związana ze stroną jest zatem jaskinią pełną skarbów, składanych tam przez wieki, do której przyciągają dziś badaczy nowe możliwości, takie jak analiza cech materialnych dzieła czy elementów niewerbalnych biorących udział w jego narodzinach. Ale czy tak samo będzie jutro? Trudno znaleźć odpowiedź na to pytanie, ponieważ na historię pisania mają wpływ zmiany, które nadciągnęły z zupełnie innej strony. Jej bieg wyznacza obecnie maszyna do liczenia - niejako mimochodem, ponieważ pisanie tekstów literackich nigdy nie było jej zadaniem. Na początku szok był ogromny: strona została zredukowana do wiersza przesuwającego się w maszynie do pisania. Sytuacja zmieniła się, gdy pierwsze komputery PC otworzyły swoje okna na świat. Sprzedawano je jako urządzenia biurowe i oprogramowanie, na którym piszę ten tekst (Word XP), nosi jeszcze znamiona tego przeznaczenia: umieszcza z automatu formułę „Szanowny Panie, Szanowna Pani” na początku każdej korespondencji i sugeruje, że nie powinienem używać czasu przeszłego prostego (passé simple) jako zbyt archaicznego. Prawdziwe programy do pisania pojawiły się zaledwie kilka lat temu i, pod wielce obiecującymi nazwami: Pages, iBooks Author (oba na licencji Apple'a), dodają liczne funkcjonalności - notatki, komentarze, szkice - do tych, które już znamy i które bardzo często symulują manualne czynności. Ale strona nie istnieje. Świat elektroniki zlikwidował większość jej funkcji. Ekran nie jest już przedmiotem podlegającym materialnej manipulacji, jego przestrzeń nie jest dostępna, lecz narzucona przez zaprogramowane urządzenie, jego ramy rozmyte przez możliwość zmiany ustawień i proporcji. Ewolucja tego wirtualnego świata postępuje zresztą tak szybko, że niektóre zjawiska, takie jak cywilizacja zredukowana do obrazu i dźwięku, mają rodowód bardziej w uniwersum science fiction niż w naukowych prognozach. Co oznacza, że równie dobrze możemy wyobrazić sobie rozwiązania, które przywracają stronie jej funkcjonalności i wzbogacają ją o nowe, jakich na razie jeszcze nie potrafimy przewidzieć.

Być może warto w tym momencie przywołać krótką fikcję retrospektywną: wyobraźmy sobie, że komputer pojawia się na pulpicie średniowiecznego mnicha. Narzędzie wydaje mu się początkowo archaiczne, nawiązujące do zwoju, gdy on przyzwyczaił się już do kodeksu. Ale ma dzięki niemu dostęp do modnych krojów: jak choćby Antiqua, Gothic, Roman, strony są łatwe w kopiowaniu (za sprawą drukarki), a funkcjonalność sterowania urządzeniem za pomocą głosu (tzw. komendy głosowe) jest wyjątkowo wygodna. Wszystko w gruncie rzeczy świetne i dostosowane do potrzeb skryptorium. Wbrew pozorom ten drobny żart sytuacyjny nie jest wcale taki bezpodstawny. Uzmysławia nam, co w historii jest zmienne, a co wieczne, pod warunkiem jednakowoż, że poczyni się pewne założenia: o trwałości języka i sztuki, którą ów ustanawia, i o niezmienności siły pisania. Reszta wydaje się nieprzewidywalna. A jednak... W chwili gdy piszę te słowa, pojawiają się zapowiedzi rea- 
lizacji dużego tabletu, na którym będzie można - co stanowi nowość - pisać ręcznie niczym na stronie. Jak na razie to jeszcze tajemnica handlowa, ale gdy ukaże się 37. numer „Genesis”, będziemy mogli znaleźć ów przedmiot na półkach sklepowych ${ }^{30}$. Informatyka odtwarza zatem nie stronę (jak chce Historia), ale nośnik dużo starszy, a po prawdzie najstarszy: tabliczkę, którą znali już Egipcjanie w czasach faraońskich. Koło wydaje się zatoczone, z jedną dość istotną jednak różnicą: za pomocą ptolemejskich tabliczek nie dało się dzwonić.

przet. Lucyna Mazur

Pierwodruk: Louis Hay, Défense et illustration de la page, „Genesis” 2013, nr 37: Verbal-Non verbal, s. 33-53.

\section{Bibliografia}

Barsht K., Dostoïevski. Du dessin à l'écriture romanesque, Paris 2004.

Bustarret C., Les manuscrits littéraires comme objet matériel: l'approche codicologique [w:] Manuscrits littéraires du XXe siècle, red. M. Sagaert, Bordeaux 2005.

Bustarret C., Usages des supports d'écriture au XVIII ${ }^{e}$ siècle: une esquisse codicologique, „Genesis” 2012, nr 34: Brouillons des Lumières.

Chartier R., Du codex à l'écran. Les trajectoires de l'écrit [w:] Pour une nouvelle économie du savoir, „Solaris. Dossier du Grisic” 1994, nr 1.

Christin A.-M., L'Invention de la figure, Paris 2011.

De la lettre au livre. Sémiotique des manuscrits littéraires, red. L. Hay, coll. „Textes et Manuscrits", Paris 1989.

Démonet J.-F., The Anatomy of Phonologic and Semantic Processing in Normal Subjects, Oxford 1992.

Ferrer D., The Open Space of the Draft Page: James Joyce and Modern Manuscripts [w:] The Iconic Page in Manuscript, Print and Digital Culture, red. G. Bornstein, Th. Tinkle, Ann Arbor 1998.

Ferrer D., Writing Space [w:] Making Space in the Work of James Joyce, red. V. Bénéjam, J. Bishop, New York 2011.

Hay L., Images du manuscrit, „Letteratura \& Arte” 2008, nr 6.

Language and Beyond, red. P. Joret, A. Remael, Amsterdam 1998.

L'Aventure des écritures. La Page, red. A. Zali, Paris 1999.

30 Numer 37. „Genesis” wraz z tekstem Louisa Haya wyszedł drukiem 16 grudnia 2013 roku. W 2013 roku firma Apple pracowała nad modelem tabletu (IPad) z odręcznym „rysikiem” (Apple Pencil); podobne rozwiązania wprowadził Samsung, producent m.in. telefonów komórkowych. 
L'Aventure des écritures. Matières et formes, red. S. Breton-Graveau, Paris 1998.

Lebrave J.-L., Du visible au lisible: comment représenter la genèse?, „Genesis” 2006, nr 27.

Les Débuts du codex, red. A. Blanchard, Turnhout 1989.

Lumbroso O., Mitterand H., Les Manuscrits et les dessins de Zola, t. III: L'invention des lieux, Paris 2002.

Mise en page et mise en texte du livre manuscrit, red. H.-J. Martin, J. Vezin, Paris 1990.

Müller L., Weiße Magie. Die Epoche des Papiers, München 2012.

Olive Th., Lebrave J.-L. et al., La dimension visuo-spatiale de la production de textes: approches de psychologie cognitive et de critique génétique, „Langages” 2010, nr 177.

Petrucci A., La scrittura del testo, „Letteratura Iitaliana” 1985, t. IV.

Pickering R., Paul Valéry. La page. L'écriture, Clermont-Ferrand 1992.

Romano A., Il codice degli Abozzi di Francesco Petrarca, Roma 1955.

Roux F.-E. et al., The Graphemic/Motor Frontal Area, „Annals of Neurology” 2009, t. LXVI, nr 4.

Séginger G., Chorégraphies scripturales de Flaubert. De l'inspiration à l'aspiration, „Genesis” 1997, nr 11.

Sirat C., Du rouleau au codex; Le parchemin [w:] Le Livre au Moyen Age, red. J. Glénisson, Paris 1988.

Spuren erzeugen: Zeichnen und Schreiben als Verfahren der Selbstaufzeichnung, red. B. Wittmann, Diaphanes, Zürich 2009.

Stendhal, Édition reproduisant la totalité des croquis de l'auteur, texte établi par Henri Martineau, Garnier 1953 (wyd. pol.: idem, Życie Henryka Brulard, przeł. i wstępem opatrzył T. Żeleński Boy).

Vattasso M., I codici Petrarcheschi della Biblioteca Vaticana, Roma 1908.

Welten schaffen. Zeichnen und Schreiben als Verfahren der Konstruktion, red. J. Voorhoeve, Zürich 2011.

Periodyki

„editio” 2008, nr 22.

„Genesis” 1996, nr 10: Sémiotique; 2012, nr 34: Brouillons des Lumières.

„Romantic Review” 1995, nr 86 (3).

„Yale French Studies” 1996, nr 89: Drafts. 